\title{
What does the general public expect from a night-sky observation?
}

\author{
Patrícia Figueiró Spinelli1 ${ }^{1,1}$, Taysa Bassallo da Silva ${ }^{2,3}$, Sonia $\mathrm{Mano}^{3}$, Alice Ribeiro ${ }^{1}$. \\ ${ }^{1}$ Museu de Astronomia e Ciências Afins, Coordenação de Educação em Ciências, Rua General Bruce \\ 586, Rio de Janeiro, Brazil \\ 2 Observatório Nacional, Rua General José Cristino 77, Rio de Janeiro, Brazil \\ 3 Museu da Vida, Fundação Oswaldo Cruz (Fiocruz), Av. Brasil, 4365 - Manguinhos, Rio de Janeiro, \\ Brazil
}

\begin{abstract}
The Night-Sky Observation Program (POC, acronym in Portuguese for Programa de Observação do Céu) is the most traditional education activity run by the Museum of Astronomy and Related Sciences (MAST). It takes place twice a week and has an annual participation of 2,400 people. It starts with a brief talk and is followed by the observation with MAST's telescopes (one of them being over a century old and other modern amateur models). The present work is the first research conducted aimed at POC's evaluation according to the participants' perspectives in its 33 years of existence. The data were collected using two instruments: a questionnaire, distributed to the participants prior to the activity, and an interview, conducted after the observations. We analysed the data using the Discourse of Collective Subject methodology, which allowed us to understand thoughts and values of the participants on a given topic. We find that the participants have the habit of gazing at the sky, even if for contemplation purposes only, and that the talk makes the public feel more prepared to observe the sky. It was frequently mentioned, though, that the language of the talk should be more oriented to children. We also find that the public expects to observe planets, stars, and constellations, and very few of them are disappointed with the whole experience. The participants also perceive the historical value of the old refractor and declare that the activity brought them feelings of wonderment. We concluded that our instruments and methodology are suitable to evaluate similar skyobservation activities. As a next step, we will conduct a survey to identify worldwide institutions that also use historically valuable telescopes in their public observations with the goal of exchanging experiences and discussing the use of such instruments with education purposes.
\end{abstract}

\section{THE MUSEUM AND THE PUBLIC SKY OBSERVATION}

The Museum of Astronomy and related Science (MAST) in Rio de Janeiro is an institution under the Brazilian Ministry of Science, Technology and Innovation. The institution is dedicated to the production of scientific knowledge, leading research in the fields of History of Science, Museum Studies \& Astronomy Heritage, and Education in Sciences in

$1 \quad$ Corresponding author: patriciaspinelli@mast.br 
non-formal settings. MAST was originally the home for the National Observatory (ON), one of the oldest scientific institutions of Brazil. Today, the Museum occupies the historic buildings and antique telescope domes previously safeguarded by $\mathrm{ON}$, but still shares the campus with the new $\mathrm{ON}$ facilities.

The activities and exhibitions organized by MAST represent a dialogue between Astronomy, History and Philosophy. The essence of the activities offered is the interaction with visitors. During the week, MAST is mostly populated by schools' students and teachers. During the weekends, the activities aim at the general public [1].

Among the visitors, MAST most beloved activity occurs every Wednesday and Saturday nights, when the telescopes are made available for the public to gaze at the sky. This activity named as "Night-Sky Observation Program", or simply "POC" has been implemented without interruptions since the establishment of MAST itself and has the goal of offering the opportunity to observe astronomical objects to the wide public. It is conducted by a team of mediators/facilitators (undergraduates from various areas) that present a 30-minute talk called "The Sky of the Month" and is followed by the observation of the sky with the 21-centimetre refractor called "Luneta-21", a centenary instrument, and other amateur telescopes.

The talk is conducted within an auditorium, and has the goal of introducing the motion of the sky to the participants. The observation occurs at the gardens or telescope domes. Figure 1 shows the two phases of POC activity as well as the old "Luneta-21".
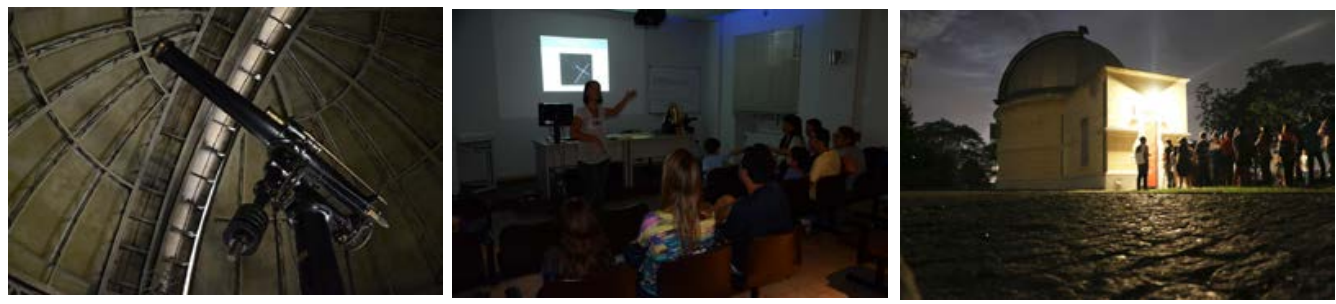

Fig. 1. Left: 21-cm centenary refractor (Luneta-21); Middle: "The Skyof the Month" talk presented at the auditorium; Right: Public lining up to observe with Luneta-21.

\section{POC'S EVALUATION - METHODOLOGY}

The main goal of this study was to evaluate the Night-Sky Observation Program - POC as well as to propose new strategies for the activity according to the participants' positive and negative feedback.

The evaluation used two instruments: a questionnaire that was answered before "The Sky of the Month" talk, when MAST visitors arrived to take part of the activity, and an interview, conducted after the observations through the telescopes. The data were collected from September until November 2015. All POC's participants with age above 15 years old were invited to take part of our research.

The closed questions were analysed using graphs. The open questions used the qualitative methodology of the Discourse of the Collective Subject (DSC, acronym in the Portuguese language for this methodology) [2]. The main advantage of this methodology is that it preserves the essence of the participants' speech. This is important because the majority of questions of both questionnaire and interviews were open.

In short, to build a collective discourse (representation of a collective speech in the firstperson singular) of each given question, it is necessary to define: (a) the key expressions of each individual discourse (selected by the researcher by being relevant to the question asked); (b) the central ideas (formulated by the researcher to join groups of key expressions that represent the same thoughts); and (c) the discourse of the collective subject, which is comprised of all key expressions belonging to the same central idea. To each collective 
discourse it is possible to attribute an intensity (frequency) "I" that indicates the total number of key expressions that comprises the discourse.

We managed to collect 119 questionnaires and 31 interviews. All people who were interviewed had also answered to the questionnaire. Unfortunately, the majority of the participants who answered the questionnaire were not interviewed, because of various reasons, namely: (1) lack of mediators/researchers to conduct the interviews - it was not possible to conduct various interviews simultaneously; (2) sudden change of meteorological conditions during the course of the activity; (3) drop-out - sometimes visitors observed through the telescope quickly and left the Museum without the mediators/researchers noticing, other times they did not want to participate in the interviewing process (this happened mostly when the respondents were parent with small kids). Table 1 summarizes the design of this research.

Table 1. Design of POC's evaluation.

\begin{tabular}{|c|c|c|}
\hline Goal & $\begin{array}{c}\text { Instrument 1 } \\
\text { Questionnaire }\end{array}$ & $\begin{array}{c}\text { Instrument 2 } \\
\text { Interview }\end{array}$ \\
\hline $\begin{array}{c}\text { To understand the visitors' } \\
\text { expectations } \\
\text { and familiarity with the night- } \\
\text { sky observation }\end{array}$ & $\begin{array}{c}\text { To evaluate the POC's } \\
\text { activity }\end{array}$ \\
\hline $\begin{array}{c}\text { Time of data } \\
\text { collection }\end{array}$ & $\begin{array}{c}\text { Pre-activity: } \\
\text { Prior to "The Sky of the Month" } \\
\text { talk }\end{array}$ & $\begin{array}{c}\text { Post-activity: } \\
\text { After the night-sky } \\
\text { observation }\end{array}$ \\
\hline $\begin{array}{c}\text { Location where the } \\
\text { data were collected }\end{array}$ & Auditorium & $\begin{array}{c}\text { Gardens or Luneta-21's } \\
\text { dome }\end{array}$ \\
\hline Format & $\begin{array}{c}\text { Self-administered with open and } \\
\text { closed questions }\end{array}$ & $\begin{array}{c}\text { Conducted by a researcher } \\
\text { with open questions, only }\end{array}$ \\
\hline Respondents & 119 & 31 \\
\hline
\end{tabular}

\section{RESULTS}

In this section we present the most relevant questions and answers for the International Symposium on Education in Astronomy and Astrobiology (ISE2A) context. The complete research and results are described by Bassallo (2016) [3].

\subsection{Participants' expectations and familiarities with the sky-observation}

Figure 2 shows the answers to the question "do you observe the sky? when?". We obtained 108 valid responses. The majority of the participants say that they always gaze the sky at night to look at the stars (59). A group of respondents stated that they observe the sky "to check the meteorological conditions" (23), pointing to a pragmatic vision of the observation. Many have indicated they observe the sky when there is a chance of better visibility, such as "when I go upcountry" (12) or "when there is a power shortage" (3). This is understandable if one considers a city as large as Rio de Janeiro, where the light pollution compromises the sky purity. A third group usually observes under specific circumstances, such as "when I am alone and want to think about life" (9) or "when I am stressed" (8), linking the sky-observation to a moment for relaxing and lowering stress. Other answers pointed to a social use of this moment, such as "when I am with my family or friends" (7) or "when I have a telescope" (3). More general aspects were pointed out by nine visitors, 
such as "to know when to cut my hair (3)"2 and "to look for unidentified flying objects (UFOs) (6)".

Fig. 2. Answers to the question "do you observe the sky? when?".

When asked "have you ever observed the sky through a telescope? how did you like it?", for those who answered "yes" (49), the most frequent words used to describe the experience were: exciting, indescribable, gratifying, transcendental, incredible, disconcerting and wonderful, all of them bringing a connotation of wonder with the lived experience. Other words such as: interesting, cool, good, great, excellent, captivating, fun and pleasant, were also mentioned but with lower frequency ${ }^{3}$.

When asked "what do you expect to observe today?", the words "planets" and "stars" were equally frequent, followed by "constellations". Other less frequent words were related to specific objects, like "Saturn" or "Jupiter" or specific stellar clusters and stars.

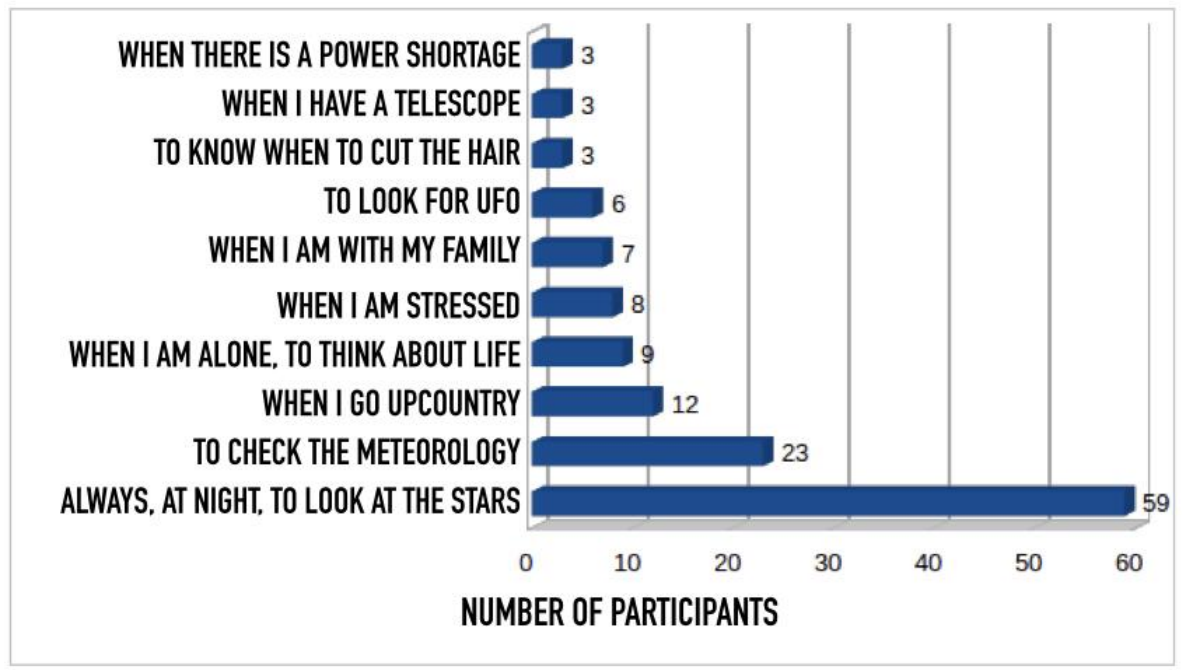

\subsection{Participants' evaluation}

In the following we present parts of the discourses of four questions related to the POC activity. The constructed discourses are not the speech from a single individual, but a collection of statements (key expressions) from various individuals that belong to the same central idea, which when summed up, yield in the intensity "I" of the specific collective discourse. It is important to emphasize that the researcher does not change the way the statements are told by the individuals, preserving the idea of a normal conversation between the participant and the interviewer. Table 2 summarizes the results to the question "was the talk 'The Sky of the Month' helpful in the observation process?"

2 In Brazil, it is a popular belief that the hair growth is associated with the Moon phases, using the tidal force of the Moon on hair as an explanation to support this misconception.

3 We have used a word cloud to analyse this question, however, since the research was conducted in Portuguese, the cloud would lose the meaning if presented here. 
Table 2. Discourses and central ideas obtained when asked "was the talk 'The Sky of the Month' helpful?

\begin{tabular}{|c|l|}
\hline $\begin{array}{c}\text { Central Ideas } \\
\text { and Intensity }\end{array}$ & \begin{tabular}{l}
\multicolumn{1}{c|}{ Discourses } \\
\hline Yes. The talk was super cool, it made a lot of difference. It was essential. I had no \\
idea what I was going to observe and she (the mediator) gave us an orientation of \\
what we would observe, what was visible, what planets we would see... that gives \\
security. She gave me information, things that I did not know and made me \\
understand the stars better. Before (coming here) I gazed the sky, but I had no \\
idea what I was looking at, I couldn't identify anything, only the Moon. With the \\
talk, I gained a new perspective, I was given basic notions and better preparation \\
to observe. I left (the auditorium) and went out straight looking for the \\
constellations... I managed to find Antares and the Scorpion. I even found Saturn! \\
Without the talk, I would get here and see a lot of "white dots" in the sky and I \\
wouldn't have known what it was. I learned a lot with the talk...
\end{tabular} \\
\hline No (I=3) & $\begin{array}{l}\text { No, attending the talk was indifferent to me. I actually came to observe. I was so } \\
\text { focused to observing that I could have gone upstairs (at the gardens and domes) } \\
\text { immediately, without stopping by the auditorium. }\end{array}$ \\
\hline \multirow{5}{*}{ Maybe (I=7) } & $\begin{array}{l}\text { In general, yes, but I say "no" because of the moment when he (the mediator) } \\
\text { began to answer the questions. There were some questions off topic. I think this } \\
\text { indeed makes the experience more informative and positive, but for the children } \\
\text { there... I think it got a bit boring, since they will only be familiar with these } \\
\text { (concepts) if they have a handier experience. }\end{array}$ \\
\hline
\end{tabular}

When asked "what objects have you observed?", the answers were Saturn, Moon, Alpha Centauri and stellar clusters. The only object that respondents elaborated on were the clusters for which the collective discourse is presented in Table 3.

Table 3. Discourse on the observation of stellar clusters.

\begin{tabular}{|c|l|}
\hline $\begin{array}{c}\text { Central Ideas } \\
\text { and Intensity }\end{array}$ & \multicolumn{1}{c|}{ Discourse } \\
\hline & $\begin{array}{l}\text { I saw a real cluster... something like little balls. They (the mediators) told us it } \\
\text { was a cluster of stars, but I cannot remember the name. One was near the }\end{array}$ \\
$\begin{array}{c}\text { Stellar } \\
\text { clusters } \\
(\mathrm{I}=11)\end{array}$ & $\begin{array}{l}\text { Southern Cross and I think it was a... "jewellery thing" (Jewel Box). And the } \\
\text { other was "M something". I remember it was an open stellar cluster, which is } \\
\text { close to the Scorpion's tail and is very, very cuddly. Even not remembering the } \\
\text { names correctly... it was exciting to look at! It was unique, it's so beautiful... I } \\
\text { always want to keep it in my memory. }\end{array}$ \\
\hline
\end{tabular}

The discourses and central ideas related to the question "did the sky-observation through the telescope meet your expectations?" are presented in Table 4.

Table 4. Discourses and central ideas obtained when asked "did the observation through the telescope meet your expectations?"

\begin{tabular}{|c|c|}
\hline $\begin{array}{c}\text { Central Ideas } \\
\text { and Intensity }\end{array}$ & \multicolumn{1}{c|}{ Discourses } \\
\hline Yes $(\mathrm{I}=26)$ & $\begin{array}{l}\text { Yes, it was a unique, fantastic, unforgettable experience! Seeing the universe... is } \\
\text { a mystery, right? I could not have lived this life without doing it, it was very } \\
\text { gratifying to participate in this observation. It's exciting because you can see very } \\
\text { closely the things that without the telescope you cannot see. We see the object as }\end{array}$ \\
\hline
\end{tabular}




\begin{tabular}{|l|l|}
\hline & $\begin{array}{l}\text { it is, it's different from seeing fake images on the internet, very cool! An } \\
\text { incredible technology, I feel like buying a telescope! [...] }\end{array}$ \\
\hline \multirow{3}{*}{ No (I=5) } & $\begin{array}{l}\text { I thought I would see more, like the entire sky or something like the Sertão's sky } \\
\text { (backwoods)... well, it was a fantasy I myself have created. I was a bit } \\
\text { disappointed, because I thought I would see things closer and bigger. But when I } \\
\text { was able to focus on the image, it was very exciting, even though it was small. Of } \\
\text { course, when they (mediators) told me that I would observe a cluster, I thought I } \\
\text { would see more, like those spark dots inside my eye, you know what I mean, } \\
\text { right? But the fact that I saw those little stars made it a good experience, it was } \\
\text { worth coming. After all, when I look at the sky (with naked eye) I cannot see } \\
\text { that! }\end{array}$ \\
\hline
\end{tabular}

The discourses and central ideas related to the question "which instrument did you like better? the old $21-\mathrm{cm}$ or the modern amateur model?" is presented in Table 5.

Table 5. Discourses and central ideas obtained when asked "which instrument did you like better? the old 21 -cm or the modern amateur model?"

\begin{tabular}{|c|l|}
\hline $\begin{array}{c}\text { Central Ideas } \\
\text { and Intensity }\end{array}$ & \multicolumn{1}{c|}{ Discourses } \\
\hline \multirow{2}{*}{$21 \mathrm{~cm}(\mathrm{I}=19)$} & $\begin{array}{l}\text { I liked the old refractor better, because it's a different thing, that we do not get in } \\
\text { contact apart from here! It has something so imposing that impressed me by size. } \\
\text { And yet, it's a hundred years old! It's very exclusive and old, but at the same } \\
\text { time, it's well preserved and has great quality. [...] I do not know if it was the } \\
\text { room, or the old refractor, but I know I liked it more. I think the 21cm's } \\
\text { environment makes a difference. That thing of entering in a dark room, seeing } \\
\text { almost nothing, climbing the ladder and reaching the refractor, where the only } \\
\text { light is the one that is coming out of that little hole that you will look... it looks a } \\
\text { bit magical! It seems like I'm a real observer, like a scientist! I felt like an } \\
\text { astronomer. And further, it's more romantic, brings other kind of emotions! } \\
\text { Creates that feeling of "wow"... I was delighted! }\end{array}$ \\
\hline $\begin{array}{c}\text { Modern } \\
(\mathrm{I}=12)\end{array}$ & $\begin{array}{l}\text { I liked more observing with the amateur model. With the refractor is a little } \\
\text { difficult to observe, because you get a bit clumsy. The amateurs' telescope is } \\
\text { more modern, handier, more direct. You arrive, you observe and you're done! It } \\
\text { brings you closer to our day to day lives: you can make some research and buy } \\
\text { one. [...] I really enjoyed it, if I could, I would come here to observe always or I } \\
\text { would have one at home. }\end{array}$ \\
\hline
\end{tabular}

\section{DISCUSSION AND CONCLUSIONS}

This study evaluated the Night-sky Observation Program run by the Museum of Astronomy and Related Sciences according to the participants' perspectives. The majority of the participants have the habit of observing the sky and want to look at the planets and stars, as well as constellations. Most of them were satisfied and very few are disappointed with the whole experience.

We concluded that "The Sky of the Month" talk is indeed an important part of POC, but some aspects should be improved. Avoiding off topic discussions is essential to keep the attention of all participants, especially children. Perhaps, a good strategy to answering questions that are not related with the motion of the sky is to do it when the talk is over, dedicating exclusive attention to the participants who have inquiries on general astronomy afterwards. It is also clear MAST should develop a specific POC activity oriented to kids.

Participants liked to observe with both Luneta-21 and modern telescopes, having a slight preference for the centenary refractor. It is interesting to notice that the participants perceive the historical value of the Luneta- 21 and declare that the activity brought feelings of wonderment. The fact that the Luneta-21 was also used to conduct astronomical research 
in the past made some people feel "like real observers, scientists, astronomers". The perception of POC participants towards the historical value of Luneta-21 was also found by previous authors. Costa's [4] study showed that

the recognition by the public of the historical value of the object and of its authenticity makes them define their contacts with it as a differentiated experience in the field of emotions and feelings, which makes that experience more than a different one, but also an interesting one, since the historical value of the object is confirmed as a factor which increases the museum visitors' curiosity".

Based on our results that support other authors' findings, as a next step, we will conduct a survey to identify worldwide institutions that also use historically valuable telescopes in their public observations. Our intent is to gather information from these places and make it into a guide, which will provoke interest in the history of astronomy, and help make these institutions more popular. In addition, we want to exchange experiences and discuss the uses of such instruments with education purposes. The data collection through the survey is ongoing. We have already identified nearly 60 institutions with similar night-sky observations activities.

\section{References}

1. D. Falcão; C. A. Coimbra; S. Cazelli; M. E. Valente. "O programa educativo do Museu de Astronomia e Ciências Afins”. Rev. Ensino em ReVista, v. 20, n. 1, Uberlândia, (2013).

2. F. Lefevre and A. M. C. Lefevre. "O sujeito coletivo que fala". Caxias do Sul: Educs (2003).

3. T. Bassallo. Dissertation "Ver o universo é uma coisa única" - o Programa de Observação do Céu segundo os visitantes do Museu de Astronomia e Ciências Afins". Casa Oswaldo Cruz/Fiocruz, Museu da Vida (2016).

4. A. Costa. Dissertation "Museu de ciência: instrumentos científicos do passado para a educação em ciências hoje”. Universidade Federal do Estado do Rio de Janeiro (2009). 